\title{
ADUBAÇÃO NPK COMO PROMOTOR DE CRESCIMENTO EM ALFACE
}

\author{
Jéssika Coelho Vaz ${ }^{1}$, Aline Torquato Tavares ${ }^{2}$, Fernando Machado Haesbaert ${ }^{3}$, Irais Dolores Pascual Reyes ${ }^{4}$, \\ Pedro Henrique Lacerda Rosa ${ }^{5}$, Tiago Alves Ferreira ${ }^{6}$ Ildon Rodrigues Nascimento ${ }^{7}$
}

\section{RESUMO:}

A alface (Lactuca sativa L) é a principal hortaliça folhosa comercializada e consumida no Brasil, sendo considerada de maior valor comercial. O objetivo do trabalho foi avaliar características agronômicas da alface sob diferentes doses de adubação NPK. O experimento foi conduzido em horta urbana na cidade de Gurupi no estado do Tocantins. Utilizou-se o delineamento experimental de blocos casualizados com quatro repetições e seis tratamentos da formulação adubo NPK (05-25-15): 0;50;100;150; 200 e $250 \mathrm{~kg} \mathrm{ha}^{-1}$ do formulado. A cultivar de alface utilizada foi SVR 2005, ao qual foi avaliado: diâmetro da cabeça; produtividade; massa comercial; massa total; comprimento do caule; número de folhas comerciais e número de folhas totais. A produtividade comercial de 14,5 $\mathrm{t} \mathrm{ha}^{-1}$ foi observada na dose de 157,4 $\mathrm{kg}$ de NPK. Doses acima de $200 \mathrm{~kg} \mathrm{ha}^{-1}$ resultaram em redução de incrementos para todas as características avaliadas. O diâmetro de cabeça teve seu ponto de máxima na dose de $172,9 \mathrm{~kg} \mathrm{ha}^{-1}$ de NPK.

Palavras- chave: Lactuca sativa L., características agronômicas, adubação química, produtividade.

\section{NPK FERTILIZER AS A GROWTH PROMOTER IN LETTUCE}

\begin{abstract}
:
Lettuce (Lactuca sativa L.) is the main leafy vegetable marketed and consumed in Brazil, being considered the one with the highest commercial value. The objective of this work was to evaluate lettuce agronomic characteristics under different doses of NPK fertilization. The experiment was conducted in an urban garden in the city of Gurupi in the state of Tocantins. The experiment used a randomized complete block design with four replications and six treatments of NPK fertilizer formulation (05-25-15) being: 0; 50; $100 ; 150 ; 200$ and $250 \mathrm{~kg} \mathrm{ha}^{-1}$ of the formulated. The lettuce cultivar used in this study was SVR 2005, from which the following elements were analyzed: head diameter; productivity; commercial mass; total mass; stem length; number of commercial sheets and number of total sheets. Commercial yield of $14.5 \mathrm{tha}^{-1}$ was

\footnotetext{
${ }^{1}$ Engenheira Agrônoma, Universidade Federal do Tocantins - UFT, Rua Badejós, Chács. 69/72, Lt. 07, CEP: 77402-970, Gurupi (TO), Brasil. coelhovazjessika@gmail.com

${ }^{2}$ Engenheira Agrônoma, Dsc., Pesquisadora PNPD do Programa de Produção Vegetal da Universidade Federal do Tocantins UFT, Rua Badejós, Chács. 69/72, Lt. 07, CEP: 77402-970, Gurupi (TO), Brasil. alinet4t@ hotmail.com

${ }^{3}$ Engenheiro Agrônomo, Dsc., Professor Adjunto do Curso de Engenharia Agronômica, Universidade Federal do Tocantins UFT, Rua Badejós, Chács. 69/72, Lt. 07, CEP: 77402-970, Gurupi (TO), Brasil. fernandomh@ @mail.uft.edu.br

${ }^{4}$ Engenheira Agrônoma, Msc., Doutoranda em Produção Vegetal, Universidade Federal do Tocantins - UFT, Rua Badejós, Chács. 69/72, Lt. 07, CEP: 77402-970, Gurupi (TO), Brasil. irais121@ hotmail.com

${ }^{5}$ Graduando em Agronomia na Universidade Federal do Tocantins - UFT, Rua Badejós, Chács. 69/72, Lt. 07, CEP: 77402-970, Gurupi (TO), Brasil. pedro13hlr@gmail.com

${ }^{6}$ Engenheiro Agrônomo, Dsc., Universidade Federal do Tocantins - UFT, Rua Badejós, Chács. 69/72, Lt. 07, CEP: 77402-970, Gurupi (TO), Brasil. tiagoferreira.agro@gmail.com

${ }^{7}$ Engenheiro Agrônomo, Dsc., Professor Adjunto II na Universidade Federal do Tocantins - UFT, Rua Badejós, Chács. 69/72, Lt. 07, CEP: 77402-970, Gurupi (TO), Brasil. ildon@mail.uft.edu.br
} 
Revista Agri-Environmental Sciences, Palmas-TO, v. 5, e019003, 2019

DOI: https://doi.org/10.36725/agries.v5i0.1215

https://revista.unitins.br/index.php/agri-environmental-sciences/index

Nota Científica

ISSN 2525-4804

observed at $157.4 \mathrm{~kg}$ of NPK. Doses above $200 \mathrm{~kg} \mathrm{ha}^{-1}$ resulted in reduction of increments for all evaluated characteristics. The head diameter had its maximum point at the dose of $172.9 \mathrm{~kg} \mathrm{ha}^{-1} \mathrm{NPK}$.

Keywords: Lactuca sativa L., agronomic characteristics, chemical fertilization, productivity. 
A alface (Lactuca sativa L.) é uma cultura de porte herbáceo, caule reduzido e não ramificado. Suas folhas são arranjadas em forma de rosetas anexadas ao caule, com variação de diferentes cores e formatos, podendo ou não se fechar em estrutura de cabeça. O sistema radicular é pivotante com ramificações finas e curtas (Nick e Borém, 2016).

A alface é a hortaliça folhosa de maior importância no mundo e destaca-se como espécie de grande importância econômica e alimentar. É consumida preferencialmente na forma de saladas e como ingrediente de lanches. Suas folhas contem elevados teores de vitaminas $\mathrm{B}$ e $\mathrm{C}$, cálcio e sais minerais, além de baixo teor calórico. Embora pouco explorada, suas sementes podem ser utilizadas para produção de óleo por ser rica em vitamina $\mathrm{E}$ (Nick e Borém, 2016). Por ter de ciclo curto, o que poder ser viabiliza a exploração por vários ciclos ao longo do ano, com consequente aumento da produção e da produtividade por hectare explorado (Kano et al., 2010).

No Brasil, a alface pode ser cultivada em campo aberto, ambiente protegido, sistema hidropônico ou orgânico, pela agricultura familiar em pequenas áreas, vizinhas aos centros consumidores (cinturões verdes). São cultivados em torno de 35 mil hectares de alface no Brasil, sendo o estado de São Paulo o principal produtor (Lopes et al., 2010).

O cultivo comercial de hortaliças é uma atividade consolidada e crescente, onde a capacidade de produção intensiva em pequenas áreas atende à grande demanda que estes locais apresentam, tanto em quantidade como em qualidade de produtos hortícolas (Araújo et al., 2010). Dentre os diversos fatores que influenciam no sistema de produção da alface, o manejo da adubação merece destaque, pois afeta o seu crescimento e consequentemente a sua produção e qualidade. A alface é uma cultura altamente dependente do uso de fertilizantes, principalmente em solos tropicais. A aplicação de doses corretas, com base nos teores dos elementos no solo, é de fundamental importância tanto na viabilidade econômica do cultivo quanto na questão de poluição ou impacto ambiental (Kano et al., 2010).

Dentre os fertilizantes, se destaca o uso de formulados contendo Nitrogênio (N), Fósforo (F) e Potássio $(\mathrm{K})$, macronutrientes requeridos em grande quantidade pela cultura. $\mathrm{O} N$ é um nutriente fundamental tanto para as plantas quanto para os animais, sendo o nutriente mais exigido pelas culturas (Faquin, 1994). Na alface é o segundo elemento mineral mais extraído (Beninni et al., 2005). O P é também um nutriente bastante exigido na alface, principalmente na fase final do seu ciclo (Lana et al., 2004). A deficiência de P reduz o crescimento da planta, ocorrendo má formação da cabeça, coloração verde-opaca das folhas velhas, podendo mostrar tonalidades vermelho-bronze ou púrpura (Katayama, 1993). O K, por sua vez, tem função nas células e tecidos da planta na regulação osmótica, no balanço de cátions/ânions, nas relações hídricas na planta, na abertura e fechamento dos estômatos, no alongamento celular, na estabilização do pH no citoplasma neutralizando ânions orgânicos e inorgânicos, na síntese de proteínas, no transporte de açúcares no floema, na fotossíntese e na ativação enzimática de um grande número de enzimas (Kerbauy, 2004).

Além de tudo isso, o K nas plantas estimula o aproveitamento do nitrogênio e consequentemente aumenta a absorção, nutrição e produtividade da mesma (Viana et al., 2010). Vários estudos demonstram diferentes respostas da alface a doses de adubo mineral nitrogenado, mesmo com o uso do adubo orgânico (Cardoso e Klar, 2011). Apesar dos resultados encontrados, doses mais elevadas de NPK ainda são utilizadas ou recomendadas e adotadas pelos agricultores. Há contradições em relação à aplicação de altas dosagens, tanto pelas condições ambientais, como pelas novas cultivares lançadas (Santos et al., 2012). Diante do exposto, o trabalho tem como objetivo avaliar características agronômicas de plantas de alface submetidas à aplicação de doses do formulado NPK (5-25-15). 
O experimento foi conduzido em horta urbana familiar, localizada no município de Gurupi no estado do Tocantins, localizada nas coordenadas geográficas $11^{\circ} 43^{\prime} 45^{\prime \prime} \mathrm{S}$ e $49^{\circ} 04^{\prime} 07^{\prime \prime} \mathrm{O}$, com altitude média de $287 \mathrm{~m}$. O clima da região é caracterizado por possuir um clima tropical semiúmido e uma estação com estiagem aproximada de quatro meses, com classificação de Köppen (1928) de Aw- Tropical de verão úmido e período de estiagem no inverno.

Utilizou-se o delineamento experimental em blocos casualizados com quatro repetições e seis tratamentos constituídos por doses do adubo com formulação NPK (05-25-15), onde contém também $\mathrm{Ca}=4,8 \% ; \mathrm{S}=3,2 \% ; \mathrm{S}-\mathrm{SO}_{4}=3,2 \%$ e $\mathrm{Zn}=0,2 \%$, por ser a mais utilizada pelos produtores. As doses utilizadas foram: $0,50,100,150,200$ e $250 \mathrm{~kg} \mathrm{ha}^{-1}$ do formulado NPK. A cultivar de alface utilizada foi SVR $2005^{\circledR}$, da empresa Seminis. O experimento foi instalado em Latossolo vermelho amarelo de textura média (Embrapa, 2013). Na análise de solo, ficou demonstrado que o solo continha a seguinte composição química: $\mathrm{pH}$ (água) $=4,9 ; \mathrm{P}=4,9$ $\mathrm{mg} / \mathrm{dm}-3 ; \mathrm{K}=0,09 \mathrm{mg} \mathrm{dm}{ }^{-3} ; \mathrm{Ca}=1,9 \mathrm{cmolc} / \mathrm{dm}^{-3}$; $\mathrm{Al}=0,0$ cmolc $/ \mathrm{dm}^{-3} ; \mathrm{SB}=3,3 ; \mathrm{MO}=3,0 \% ;$ Areia $=$ $65 \%$; Silte $=7,1$; Argila $=27,8 \%$ e V\%= 44,10.

Cada unidade experimental foi formada por quatro linhas de $2,5 \mathrm{~m}$ de comprimento em canteiros de 1,00 $\mathrm{m}$ de largura. $\mathrm{O}$ espaçamento adotado foi de $0,25 \mathrm{~m} \times 0,25 \mathrm{~m}$ entre linhas e entre plantas dentro das linhas, respectivamente, totalizando 64 plantas por parcela. Foram utilizadas como parcela útil as plantas das duas linhas do centro, descartando as duas primeiras plantas da extremidade de cada linha.

As mudas foram produzidas em bandejas de poliestireno, com substrato contendo solo e esterco peneirado na proporção de 1:1. O transplante foi feito 30 dias após a semeadura, quando as mesmas atingiram de 4 a 6 quatro folhas definitivas.
A irrigação foi por aspersão do tipo convencional, realizada três vezes ao dia, com duração de cinco minutos. A colheita foi realizada aos 45 dias após o transplante, quando as plantas mostravam padrão comercial, sem sinais de florescimento e com desenvolvimento vegetativo máximo. Durante a condução do experimento não ocorreu incidência de doenças e pragas.

As características avaliadas em cada parcela foram:

- Diâmetro da cabeça $(\mathrm{cm})$ : obtido com auxílio de uma régua milimétrica em $\mathrm{cm}$, onde mediu-se o diâmetro transversal da cabeça;

- Produtividade $\left(\mathrm{t}\right.$ ha $\left.{ }^{-1}\right)$ : obtida a partir da pesagem das plantas da parcela útil e o resultado foi convertido em $\mathrm{t} \mathrm{ha}^{-1}$;

- Massa média comercial das plantas (g): obtido em balança após a retirada das folhas com aparente defeito;

- Massa média total das plantas (g): obtido em balança a partir da pesagem das plantas da parcela útil com todas as folhas;

- Comprimento do caule $(\mathrm{cm})$ : obtido com auxílio de uma régua milimétrica;

- Número de folhas comerciais: expresso pelo número de folhas sem danos visuais;

- Número de folhas totais: expresso pelo número total de folhas.

Com os valores médios de cada parcela foi feito a análise de variância e regressão com ajuste do modelo matemático mais adequado entre as variáveis dependentes (características) e independentes (doses de NPK) no software Sisvar (Ferreira, 2011).

$\mathrm{Na}$ análise de variância houve significância ao nível de $1 \%$ de probabilidade de erro para todas as características avaliadas (Tabela 1). Em geral, para todas as características, houve uma resposta quadrática do efeito da dose na sua expressão. 
Tabela 1. Resumo da análise de variância para as características diâmetro da cabeça (DC em $\mathrm{cm})$, peso comercial ( $\mathrm{PC} \mathrm{em} \mathrm{g}$ ), produtividade ( $\mathrm{PROD}$ em $\mathrm{t}$ ), comprimento do caule $(\mathrm{CC} \mathrm{em} \mathrm{cm})$, número de folhas comerciais (FC), número de folhas totais (FT).

\begin{tabular}{cccccccc}
\hline \multirow{2}{*}{ F.V } & \multirow{2}{*}{ G. $\mathbf{L}$} & \multicolumn{7}{c}{ Quadrado Médio } \\
\cline { 3 - 7 } & & DC & PC & PROD & CC & FC & FT \\
\hline Blocos & 3 & 0,18 & 80,98 & 0,91 & 0,11 & 0,94 & 0,42 \\
Doses & 5 & $33,85^{* *}$ & $3791,69^{* *}$ & $43,15^{* *}$ & $16,05^{* *}$ & $25,27^{* *}$ & $29,34^{* *}$ \\
Erro & 10 & 0,54 & 41,21 & 0,46 & 0,79 & 0,19 & 0,36 \\
\hline C.V $(\%)$ & & 3,47 & 5,73 & 5,73 & 8,3 & 3,21 & 3,63 \\
\hline $\begin{array}{c}\text { Média } \\
\text { Geral }\end{array}$ & 21,22 & 112,01 & 11,94 & 10,73 & 13,6 & 16,69 \\
NS - Não significativo, ** $\mathrm{e}^{*}$ significativo a 1\% e 5\% de probabilidade de erro respectivamente pelo teste F.
\end{tabular}

Para diâmetro da cabeça as médias variaram de 14,50 a $23,58 \mathrm{~cm}$ entre as doses de 0 a $250 \mathrm{~kg}$ ha ${ }^{1}$ de NPK, ocorrendo o ponto de máxima com dose máxima ajustada na dose de $172,9 \mathrm{~kg} \mathrm{ha}^{-1}$ resultando um num diâmetro de $23,8 \mathrm{~cm}$. (Figura 1A).

Segundo Sala e Costa (2012), a padronização do diâmetro e altura são características importantes, em relação ao transporte e acondicionamento das plantas, sendo que plantas com maiores dimensões podem ser danificadas nos processos de acondicionamento e transporte, diminuindo assim a qualidade do produto.

A massa média comercial das plantas (Figura 1B) variou de 48,86 a 139,41 g. Para essa característica, na dose de $157,1 \mathrm{~kg} \mathrm{ha}^{-1}$ houve redução da expressão da característica, com rendimento máximo de 136,3 g. Blat et al. (2011) ao avaliar dez cultivares de alface no município de Ribeirão Preto (SP), para alface crespa Vanda encontraram uma massa fresca comercial da parte aérea de 270,2 $\mathrm{g}_{\text {planta }}{ }^{-1}$. Já Santos et al. (2005) obtiveram para alface Verônica, valores de massa fresca da parte aérea de 104,16 g planta $^{-1}$, semelhante ao observado neste estudo.

$\mathrm{Na}$ produtividade houve uma variação de 5,21 a 15,34 $\mathrm{t} \mathrm{ha}^{-1}$ (Figura 2A), sendo a dose ajustada de $157,4 \mathrm{~kg} \mathrm{ha}^{-1}$ com produtividade de 14,5 $\mathrm{t} \mathrm{ha}^{-1}$. Tosta et al. (2009), verificaram que a produtividade da alface, quando cultivada em canteiros cobertos por plástico preto proporcionou maiores produtividades $\left(42,31 \mathrm{t} \mathrm{ha}^{-1}\right)$, resultados superiores ao cultivo convencional.

Para a massa total, houve uma variação de incremento de 64,9 a 172,68 g entre as doses de 0 a $250 \mathrm{~kg} \mathrm{ha}^{-1}$ de NPK, com posterior redução após a dose de $150 \mathrm{~kg} \mathrm{ha}^{-1}$ de NPK (Figura 2B).

$O$ fato da dose Testemunha, sem adição de NPK, ter ocasionado menor peso comercial, pode estar associado à deficiência de tais nutrientes, causando redução na fotossíntese, menor crescimento e consequentemente menor massa seca (Primavesi, 1985).

O comprimento do caule está associado à tolerância da cultivar ao pendoamento precoce. Houve variação de 6,21 a $12,58 \mathrm{~cm}$ sob as diferentes doses de NPK sendo a dose ajustada de $168,7 \mathrm{~kg} \mathrm{ha}^{-1}$ com 12,3 cm de caule (Figura 3A). Os resultados encontrados neste trabalho para comprimento do caule são superiores aos encontrados por Souza et al., (2008) ao estudarem progênies de alface tolerante ao calor, encontraram uma variação de 3,44 $\mathrm{cm}$ a 9,94 cm, para comprimento de caules de alface, no estado do Pernambuco, sendo uma característica que está correlacionada ao pendoamento. Houve baixa correlação entre os tratamentos que receberam adubação NPK. 

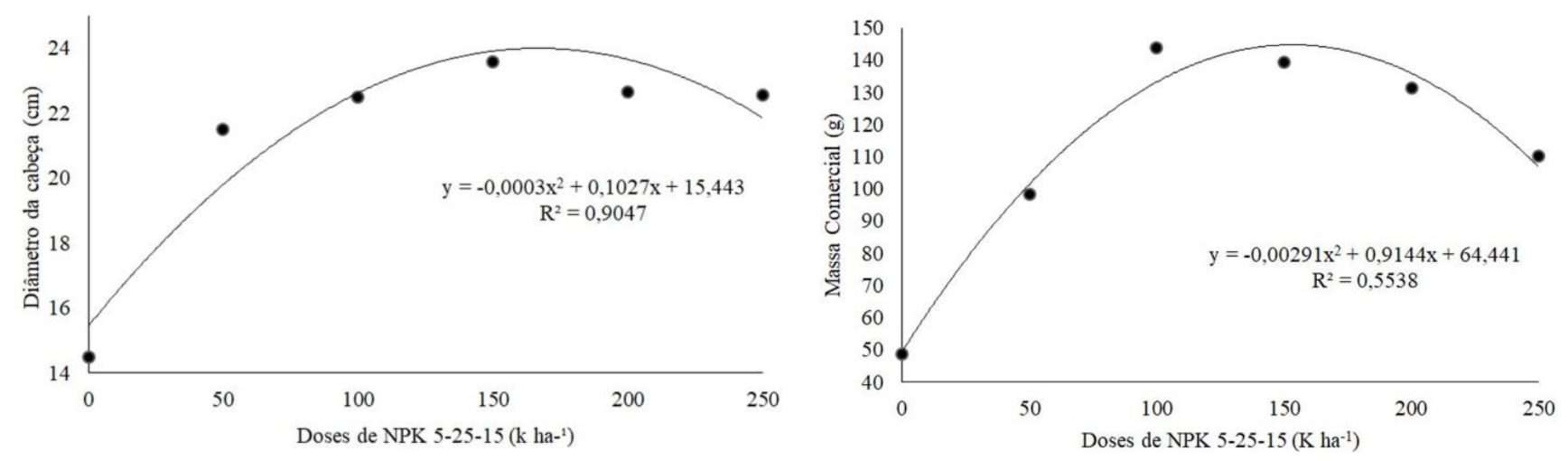

Figura 1. Diâmetro da cabeça (A) e Massa comercial (B) da cultivar SVR 2005 sob diferentes doses de NPK. Gurupi- TO, 2018.
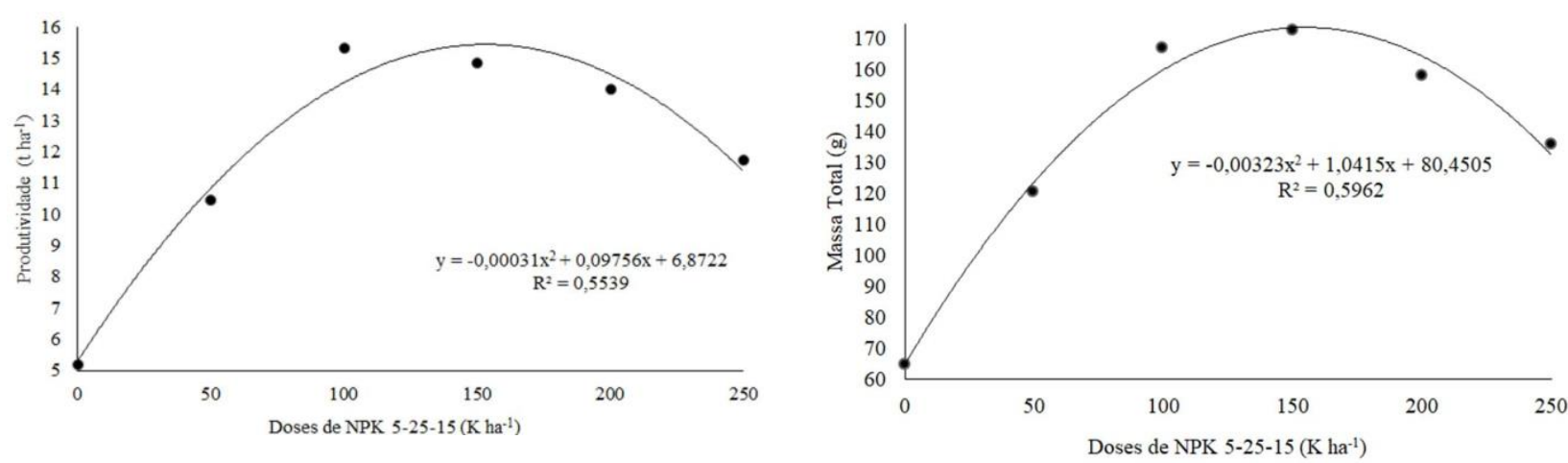

Figura 2. Produtividade (A) e Massa total (B) da cultivar SVR 2005 sob diferentes doses de NPK. GurupiTO, 2018.

Fotoperíodos longos e temperaturas elevadas (superior a $25^{\circ} \mathrm{C}$ ) estimulam o comprimento do caule e a emissão do pendão floral o que, indiretamente afetam as demais características avaliadas. A temperatura no estado do Tocantins possui temperaturas médias de $27^{\circ} \mathrm{C}$, podendo justificar o comprimento do caule neste trabalho (Santos et al., 2012).

Observou-se para a característica número de folhas comerciais uma variação de 8,17 a 16,33 folhas sob as diferentes doses de NPK, com maior incremento na dose de $150,7 \mathrm{~kg} \mathrm{ha}^{-1}$ (Figura 3B). Já as doses acima de $200 \mathrm{~kg} \mathrm{ha}^{-1}$, contribuíram para a redução nos valores do número de folhas comerciais e totais, resultado semelhante foi encontrado por Araújo et al. (2011). Segundo Filgueira (2003) o fornecimento de doses adequadas de $\mathrm{N}$ favorece $\mathrm{o}$ crescimento vegetativo, expande a área fotossintética e eleva o potencial produtivo da cultura. 

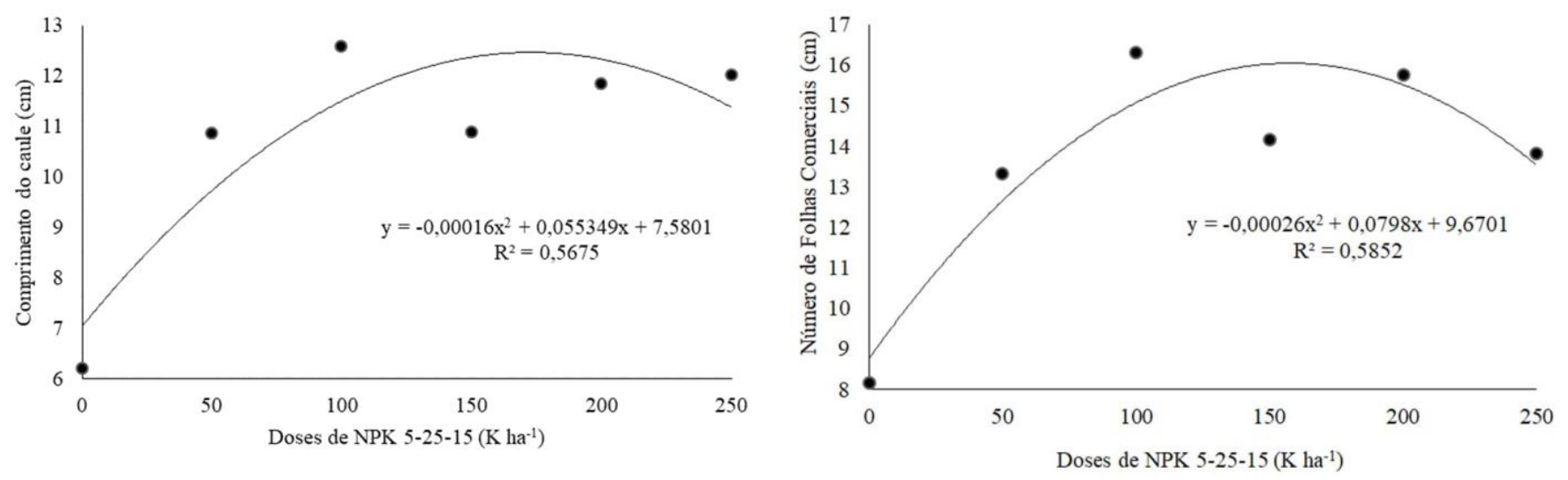

Figura 3. Comprimento do caule (A) e Número de Folhas comerciais (B) da cultivar SVR 2005 sob diferentes doses de NPK. Gurupi- TO, 2018.

Para a variável número de folhas totais observou-se uma variação de 11 a 19 folhas nas diferentes doses de NPK, com ponto de máximo na dose de 150,5 $\mathrm{kg} \mathrm{ha}^{-1}$ com 19,4 de folhas (Figura 4).
O número de folhas é uma característica genética que pode ser afetada pelo ambiente, podendo ser essa a razão pela qual houve redução na quantidade das mesmas Falconer (1987).

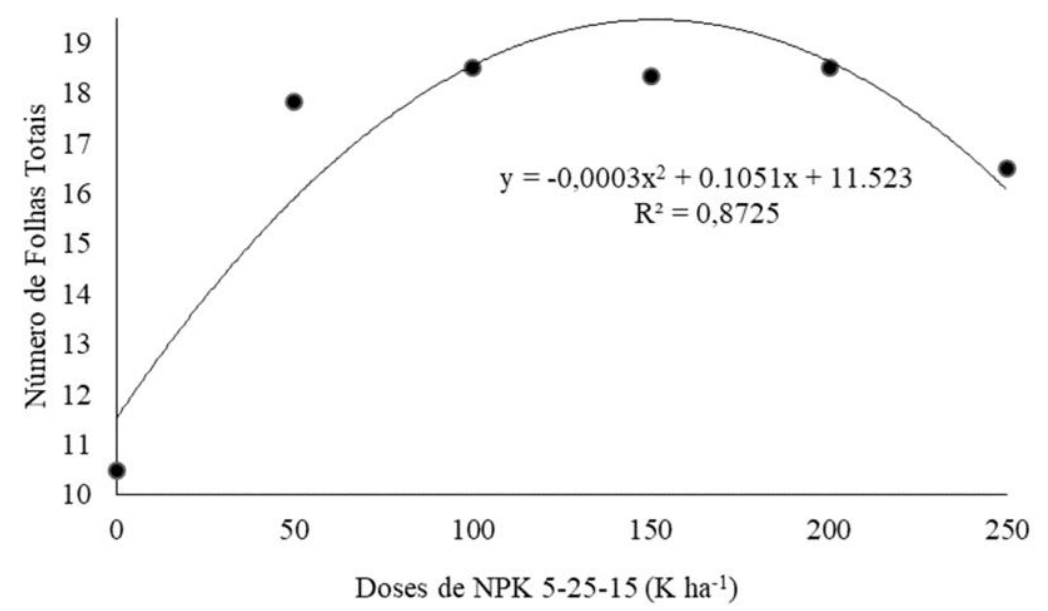

Figura 4. Número de Folhas totais da cultivar SVR 2005 sob diferentes doses de NPK. Gurupi- TO, 2018.

A produtividade comercial de $14,5 \mathrm{t} \mathrm{ha}^{-1}$ foi observada na dose de $157,4 \mathrm{~kg}$ de NPK. Doses acima de $200 \mathrm{~kg} \mathrm{ha}^{-1}$ resultaram em redução de incrementos para todas as características avaliadas. Segundo Filgueira (2003) o fornecimento em excesso de doses de $\mathrm{N}$ pode ocasionar queima das folhas em plantas novas, aumentar a susceptibilidade a doenças, deixar os tecidos mais frágeis e sujeitos a danos mecânicos, dificultar a absorção de outros nutrientes, prolongar o ciclo da cultura e retardar a colheita diminuindo a qualidade do produto. $\mathrm{O}$ diâmetro de cabeça teve uma melhor resposta na dose ajustada de $172,9 \mathrm{~kg} \mathrm{ha}^{-1}$ de NPK (5-25- 15) nas condições avaliadas.

Concluiu-se que a cultivar de alface respondeu progressivamente até doses próximas a $150 \mathrm{~kg} \mathrm{ha}^{-1}$. Nas doses superiores a $200 \mathrm{~kg} \mathrm{ha}^{-1}$ foi observado uma redução das características avaliadas.

\section{REFERÊNCIAS BIBLIOGRÁFICAS}


Araújo, W.F.; Sousa, K.T.S.; Viana, T.V.A.; Azevedo, B.M.; Barros, M.M.; Marcolino, E. (2011). Resposta da alface a adubação nitrogenada. Revista Agroambiente On-line, 5(1) 12-17. DOI: 10.18227/1982-8470ragro.v5i1.440.

Beninni, Y.E.R.; Hideaki, W.T.; Carmen, V.J.N. (2005). Concentração e acúmulo de macronutrientes em alface cultivada em Sistema hidropônico e convencional. Semina: Ciências Agrarias 26(3) 273- 282 .

Blat, S.F.; Branco, R.B.F.; Trani, P.E. (2011). Desempenho de cultivares de alface crespa em

Riberão Preto (SP) no cultivo de primavera. Pesquisa \& Tecnologia, 8(105) 1-9.

Cardoso, G.G. \& Klar, A.E. (2011). Fracionamento da fertirrigação e seu efeito na produção da alface sob ambiente protegido. Irriga, Botucatu, 16(3) 259-270.

Empresa Brasileira de Pesquisa Agropecuária EMBRAPA. Sistema brasileiro de classificação de solos. 3.ed. Brasília, 2013. 353p.

Faquin, V. (1994). Nutrição Mineral de plantas. $1^{\text {a }}$ ed. Lavras: ESAL- FAEPE. 227 p.

Falconer, D.S. (1987). Introdução à genética quantitativa. Viçosa: UFV. 359p.

Filgueira, F.A.R. Novo Manual de Olericultura: agrotecnologia moderna na produção e comercialização de hortaliças . $2^{\mathrm{a}}$ ed. Revista e ampliada. Viçosa. UFV, 2003. 412 p.

Faveri, L.A. Castoldi, R.; Charlo, H.C.O.; Braz, L.T. (2009) Desempenho de mini-alface crespa sob diferentes níveis de adubação. Horticultura Brasileira 27(2) 294-296.

Ferreira, D.F. (2011). Sisvar: A computer statistical analysis system. Ciência e Agrotecnologia, 35(6) 1039- 1042.

Kano C; Cardoso A.I.I; Villas Bôas R.L. (2010). Influencia de doses de potássio nos teores de macronutrientes em plantas e sementes de alface. Horticultura Brasileira 28(3): 287-291.
Katayama, M. Nutrição e adubação de alface, chicória e almeirão. (1993). In: FERREIRA, M. E.; Castellane, P. D.; Cruz, M. C. P. (Ed.). Nutrição e adubação de hortaliças. Piracicaba: POTAFOS. p. 141-148.

Kerbauy, G.B. (2004). Fisiologia Vegetal. $1^{\mathrm{a}}$ ed. Guanabara Koogan.452 p.

Köppen, W.; Geiger, R. (1928). Klimate der Erde. Verlag Justus Perthes, Gotha. Wall-Map $150 \mathrm{~cm} \mathrm{x}$ $200 \mathrm{~cm}$.

Lana, R.M.Q.; Zanão Júnior, L.A.; Luz, J.M.Q.; Silva, J.C. (2004). Produção da alface em função do uso de diferentes fontes de fosforo em solo de cerrado. Horticultura Brasileira, 22(3) 525- 528. DOI: $10.1590 / \mathrm{S} 0102-05362004000300004$.

Lopes, J.C.; Ribeiro, L.G.; Araújo, M.G.; Beraldo, M.R.B.S. (2005) Produção de alface com doses de lodo de esgoto. Horticultura Brasileira. Brasília, 23(1) 143-147. DOI: 10.1590/S010205362005000100030

Nick, C.; Borém, A. (2016). Melhoramento de hortaliças. $1^{\text {a }}$ ed. Editora: UFV. 464p.

Primavesi, A. (1985). Manejo ecológico do solo: a agricultura em regiões tropicais. $8^{\mathrm{a}}$.ed. São Paulo: Nobel. 541 p.

Sala, F.C.; Costa, C.P. (2012). Retrospectiva e tendência da alfacicultura brasileira. Horticultura Brasileira 30(2) 187-194. DOI: 10.1590/S010205362012000200002.

Santos F.N.; Araújo, J.R.G.; Costa, E.M.R.C.; Costa, E.P.B.C.; Silva, J.C.B.; Silva, J.R. (2005) Avaliação de cultivares de alface sob as condições de cultivos a ambiente protegido e a campo. Horticultura Brasileira 23(2) 1-4.

Santos, R.F.; Borsoi, A.; Tomazzoni, J.L.; Viana, O.H. (2012). Aplicação de nitrogênio da cultura da alface. Revista Varia Scientia Agrárias 2(2) 69-77.

Souza, M.C.M.; Resende, L.V; Menezes, D.; Loges, V.; Souto, T.A.; Santos, V.F. (2008). Variabilidade genética para características agronômicas em progênies de alface tolerantes ao calor. Horticultura 
Brasileira 26(3) 354-358. DOI: 10.1590/S010205362008000300012.

Tosta, M.S.; Borges, F.S.P.; Reis, L.L.; Tosta, J.S.; Mendonça, V.; Tosta, P.A.F. (2009). Avaliação de quatro cultivares de alface para cultivo de outono em Cassilândia-MS. Agropecuária Científica no SemiÁrido 5(1) 30-35, DOI: 10.30969/acsa.v5i1.46.

Viana, E.M.; Kiehl, J.C. (2010). Doses de nitrogênio e potássio no crescimento do trigo. Bragantia 69(4) 975-982, DOI: $\quad$ 10.1590/S000687052010000400024 . 